\title{
Impact of body mass index on success, complications and failure of extracorporeal shock wave lithotripsy
}

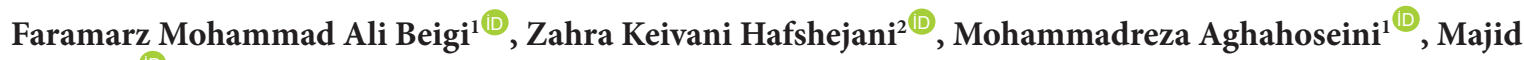 \\ Shirani $^{1^{*}(\mathbb{D})}$ \\ ${ }^{1}$ Department of Surgery, Shahrekord University of Medical Sciences, Shahrekord, Iran \\ ${ }^{2}$ Research and Technology Deputy, Shahrekord University of Medical Sciences, Shahrekord, Iran
}

\section{A R T I C L E I N F O}

Article Type:

Original

\section{Article History:}

Received: 18 March 2019

Accepted: 3 May 2019

Published online: 11 June 2019

Keywords:

Obesity

Urinary stones

Lithotripsy

Kidney stones

\begin{abstract}
A B S T R A C T
Introduction: Extracorporeal shock wave lithotripsy (ESWL) is known as the most common method in treating urinary stones $(70 \%)$ and is a selective method to treat small urinary stones $(<2-2.5 \mathrm{~cm})$. General opinion is that the success rate of ESWL in obese patients is low and risk of complications is high.

Objectives: The aim of this study was to evaluate the impact of body mass index (BMI) and the stone-to-skin distance on success, complications and failure of ESWL.

Patients and Methods: In this study, 222 patients who referred to lithotripsy clinic of Kashani hospital of Shahrekord to break stones with diameters of 5 to $20 \mathrm{~mm}$ participated in the study. Their urinary stones were in kidneys, lower calyces, upper calyces, pelvis or proximal ureter and were divided into two equal groups of BMI $>25 \mathrm{~kg} / \mathrm{m}^{2}$ and BMI $<25 \mathrm{~kg} / \mathrm{m}^{2}$. Assessing the position and diameter of the stones was based on radiographic findings such as sonography and CT scan. Regarding success, failure and complications of lithotripsy, two groups were compared.

Results: Around 105 and 117 patients out of 222 subjects, were respectively assigned in BMI $>25 \mathrm{~kg} /$ $\mathrm{m}^{2}$ and $\mathrm{BMI}<25 \mathrm{~kg} / \mathrm{m}^{2}$ groups. The failure and success of both groups were statistically significant $(P=0.023)$. In terms of treatment outcomes, difference between two groups was high in low skinto-stone distance (SSD). Logistic regression showed that both BMI and SSD are effective factors in treating the stone while SSD was more effective $(P=0.004)$ than BMI $(P=0.023)$ since SSD $>7.5 \mathrm{~cm}$ predicts treatment failure.

Conclusion: BMI and SSD are effective factors on the outcome of ESWL. Higher BMI and SSD> 7.5 $\mathrm{cm}$ are effective factors on treatment failure.
\end{abstract}

Implication for health policy/practice/research/medical education:

In a study on 222 patients who referred for lithotripsy, we found BMI and skin-to-stone distance are effective factors on the outcome of ESWL. Higher BMI and skin-to-stone distance $>7.5 \mathrm{~cm}$ are effective factors on treatment failure.

Please cite this paper as: Ali Beigi MF, Keivani Hafshejani Z, Aghahoseini M, Shirani M Impact of body mass index on success, complications and failure of extracorporeal shock wave lithotripsy. J Renal Inj Prev. 2019;8(3):221-224. DOI: 10.15171/jrip.2019.41.

\section{Introduction}

Kidney stones and urinary tract are one of the most common problems (1). More than $5 \%$ of adults in the United States are suffering from kidney stones, and its prevalence is increasing (2). Urinary tract stones are more common in males than females so that men are afflicted with urinary stones four times more than women. In a recent study in the United States, it has been reported that the prevalence of urinary stones has been increased five times over the last ten years in the United States (3). After the first stone is formed, stone recurrence is very high. Its risk is more than $50 \%$ during the next 5 to 10 years after the formation of the first stone (4). In recent years, economic and social development in communities has been caused to decrease and increase bladder stones in children and kidney stones in adults, respectively. Both in the past and today, urinary stones are composed of calcium oxalate, ammonium urate or uric acid. In some parts of the Middle East, India and North Africa, urate stones are more common (3). Epidemiological studies indicate that urinary stones can be created in both rich and poor class. Diet composition is important in both groups. Economic and social development and industrialization have been caused to improve diet and consumable foods are full of high-protein and refined carbohydrates in these areas. In these areas, the prevalence of stone in upper urinary tract that is mostly calcium oxalate has been increased and bladder stones have been decreased 
in children (4). Urinary stones are showed with colic pains, nausea, vomiting and hematuria. It is possible that stones causing severe blockage in the urinary tract lead to hydronephrosis, renal failure and destruction (5). The risks of extracorporeal shock wave lithotripsy are renal vascular injury and resultant scars, hypertension, creating brushite stones (a type of stone that is created in damaged space of urinary epithelium) and perirenal hematoma which is considerably less than invasive methods such as percutaneous nephron lithotomy or surgery (6). Obesity is a growing epidemic that has created many problems in the field of medical diagnosis and treatment. Overweight is identified with a body mass index (BMI) $>25 \mathrm{~kg} / \mathrm{m}^{2}$ while obesity is determined with BMI >30 $\mathrm{kg} / \mathrm{m}^{2}(7)$. The prevalence of obesity and overweight in the United States has been increased to $61 \%$ that $30 \%$ are suffering from obesity (8). Obesity is a risk factor in creating kidney stones. Obesity is a limit for diagnosis and treatment options. CT scan tables, MRI, fluoroscopy and lithotripsy have weight limitation. Patients weighing more than 300 pounds are likely inappropriate to diagnostic and therapeutic procedures with these devices. Standard lithotripsy has a focal length less than $15 \mathrm{~cm}$ between the power source and target F2 that sometimes makes it impossible to treat obese patients (9). Extracorporeal shock wave lithotripsy (ESWL) is more difficult in patients who have skeletal deformities or they are very obese and these factors disturb the focus of shock waves to the stone (3). Treating kidney stones in obese patients is among the challenges of urology. In most equipped centers, RIRS (retrograde intrarenal lithotripsy) method is recommended to treat this group of patients. On the other hands, the beds of ESWL are not designed for overweight patients while it is assessed that the success rate of ESWL in obese patients is less and its complications are more. However, a few academic studies have been conducted about ESWL in overweight patients while sometimes contradictory results have been reported.

\section{Objectives}

The prevalence of obesity in our country and lack of access to methods such as RIRS in the majority of treatment centers has increased (10). This study was aimed to investigate the effect of BMI on the success and complications of ESWL.

\section{Patients and Methods \\ Study population}

In this study, 222 patients who referred to lithotripsy clinic of Kashani hospital of Shahrekord to break renal stones with diameters of 5 to $20 \mathrm{~mm}$ participated in the study (February to July 2015). Their urinary stones were in kidneys, lower calyces, upper calyces, pelvis or proximal ureter. Patients' weight and height and consequently their BMI were calculated. Where the stone is located, the size of stone, stone-to-skin distance and the history of heart diseases, medications and date of conducting ESWL were recorded in the form of each patient. Other demographic information of patients was collected by using patient information forms by the researcher. Patients were being cared for 2 to 4 weeks after the first session of lithotripsy. Patients' stone free rate was measured by using medical imaging tools and para-clinic evaluation such as sonography, and CT scans. All patients were followed by phone for ensuring them regarding their care. The success rate of lithotripsy in the first, second and third session, the failure rate of lithotripsy and complications related to ESWL were recorded in patients' form by the researcher.

\section{Ethical issues}

The research followed the tenets of the Declaration of Helsinki; informed consent was obtained from all patients. This study was approved by Ethics Committee of Shahrekord University of Medical Sciences (\#IR.SKUMS. REC.1394.97). All participants were informed about the objectives of the study and assured that the information will remain confidential. Participants also signed out consent forms. This study was conducted as the M.D. thesis of Mohammadreza Aghahoseini at this university. Accordingly, Shahrekord University of Medical Sciences supported this research financially (Grant \# 2312, 2016).

\section{Data analysis}

The data were analyzed by SPSS 22 using descriptive tests and McNemar's test. $P$ value less than 0.05 was considered as statistically significant

\section{Results}

Around 105 and 117 patients out of 222 ones were assigned as $\mathrm{BMI}<25 \mathrm{~kg} / \mathrm{m}^{2}$ and $\mathrm{BMI}>25 \mathrm{~kg} / \mathrm{m}^{2}$, respectively. The average BMI was $25.46 \mathrm{~kg} / \mathrm{m}^{2}$, minimum BMI was 15.62 $\mathrm{kg} / \mathrm{m}^{2}$ and maximum BMI was $38.05 \mathrm{~kg} / \mathrm{m}^{2}$. The average age was 43 years. The minimum and maximum ages were 17 and 82 years, respectively. The average, minimum and maximum of stone-to-skin distances were 71.69, 30 and $101 \mathrm{~mm}$, respectively. The average size, minimum size, and maximum size of stone were $11.15 \mathrm{~mm}, 5 \mathrm{~mm}$ and $20 \mathrm{~mm}$, respectively. This study was conducted on 222 patients that 138 males (62\%) and 84 females (38\%) participated in the study. There were 65 males and 40 females in the group with $\mathrm{BMI}<25 \mathrm{~kg} / \mathrm{m}^{2}$ and 73 males and 44 females in the group with BMI> $25 \mathrm{~kg} / \mathrm{m}^{2}$. Treatment failure rate in normal BMI was less than the other group and difference was statistically significant $(P=0.023)$ (Table 1$)$.

To determine exactly, group BMI $>25 \mathrm{~kg} / \mathrm{m}^{2}$ was divided into two groups of overweight $\left(25<\mathrm{BMI}<30 \mathrm{~kg} / \mathrm{m}^{2}\right)$ and obese $\left(\mathrm{BMI}>30 \mathrm{~kg} / \mathrm{m}^{2}\right)$; normal, overweight, and obese groups were compared regarding treatment result and treatment complications. The difference between obese and overweight groups was significant that was due to the small number of patients in the obese group $(P=0.027$; Table 2). 
Table 1. The result of lithotripsy in two groups

\begin{tabular}{lcc}
\hline Groups & BMI $<\mathbf{2 5} \mathbf{~ k g} / \mathbf{m}^{2}$ & BMI $>\mathbf{2 5} \mathbf{~ k g} / \mathbf{m}^{\mathbf{2}}$ \\
\hline Failure & $12(11.4 \%)$ & $30(25.6 \%)$ \\
Successful in the first time & $79(75.2 \%)$ & $69(59 \%)$ \\
Successful in the second time & $11(10.5 \%)$ & $11(9.4 \%)$ \\
Successful in the third time & $3(2.9 \%)$ & $7(6 \%)$ \\
\hline
\end{tabular}

$P=0.023$.

146 patients presented in group skin-to-stone distance (SSD) $>65 \mathrm{~mm}$ and these two groups BMI $<25 \mathrm{~kg} / \mathrm{m}^{2}$ and $\mathrm{BMI}>25 \mathrm{~kg} / \mathrm{m}^{2}$ were compared similarly. Treatment outcomes in the two groups were not significantly different in patients with SSD $>65 \mathrm{~mm}(P=0.59$; Table 3$)$.

Logistic regression showed that both $\mathrm{BMI}$ and SSD are effective factors in treatment outcomes and SSD $(P=0.004)$ was more effective than BMI $(P=0.023)$.

\section{Discussion}

The aim of this study was to evaluate the effect of BMI and SSD on success, complications and failure of ESWL. In this study, we found that the rate of treatment failure in patients with normal BMI was less than other group, while the difference between the two groups was statistically significant. Hence, BMI is a factor influencing the obtained results from ESWL. Additionally, regarding treatment complications, we found no significant difference between two groups. In lower SSD and normal $\mathrm{BMI}$, the rate of treatment failure was significantly less than high BMI; however, in SSD $\geq 65 \mathrm{~mm}$ no significant difference was seen between treatment outcomes in both normal and high BMI groups. In the study conducted by Pareek et al, the success of ESWL method based on BMI and Hounsfield units was evaluated. Their study was conducted on 100 patients with stone size of 5 to $10 \mathrm{~mm}$ in the upper urinary tract which were treated with ESWL.

Table 2. The result of treatment between three groups

\begin{tabular}{|c|c|c|c|c|}
\hline Result & & $\begin{array}{c}\mathrm{BMI}<25 \\
\mathrm{~kg} / \mathrm{m}^{2}\end{array}$ & $\begin{array}{c}25<\mathrm{BMI}<30 \\
\mathrm{~kg} / \mathrm{m}^{2}\end{array}$ & $\begin{array}{c}\mathrm{BMI}>30 \\
\mathrm{~kg} / \mathrm{m}^{2}\end{array}$ \\
\hline \multirow{2}{*}{ Failure } & No. & 12 & 20 & 10 \\
\hline & $\%$ & 11.4 & 22.2 & 37 \\
\hline \multirow{2}{*}{$\begin{array}{l}\text { Successful in the first } \\
\text { time }\end{array}$} & No. & 79 & 57 & 12 \\
\hline & $\%$ & 75.2 & 63.3 & 44.4 \\
\hline \multirow{2}{*}{$\begin{array}{l}\text { Successful in the } \\
\text { second time }\end{array}$} & No. & 11 & 8 & 3 \\
\hline & $\%$ & 10.5 & 8.9 & 11.1 \\
\hline \multirow{2}{*}{$\begin{array}{l}\text { Successful in the third } \\
\text { time }\end{array}$} & No. & 3 & 5 & 2 \\
\hline & $\%$ & 2.9 & 5.6 & 7.4 \\
\hline
\end{tabular}

Table 3. Comparison of treatment in two groups of BMI in SSD> $65 \mathrm{~mm}$

\begin{tabular}{lcc}
\hline Groups & BMI $<\mathbf{2 5} \mathbf{~ k g} / \mathbf{m}^{\mathbf{2}}$ & BMI $>\mathbf{2 5} \mathbf{~ k g} / \mathbf{m}^{\mathbf{2}}$ \\
\hline Failure & $11(19.6)$ & $25(27.8)$ \\
Successful in the first time & $34(60.7)$ & $52(57.8)$ \\
Successful in the second time & $8(14.3)$ & $8(8.9)$ \\
Successful in the third time & $3(5.4)$ & $5(5.6)$ \\
\hline
\end{tabular}

BMI was measured for each patient. Hounsfield unit value and chemical composition analysis were conducted for each stone too. They found BMI and Hounsfield unit are effective parameters on lithotripsy results which is consistent with our study (11).

In a retrospective study by Olivi et al (12), the results of ESWL method on patients with BMI over $35 \mathrm{~kg} / \mathrm{m}^{2}$ were evaluated. They detected, treatment of urinary stones in very severely obese patients is associated with higher morbidity since ESWL is a proper method to clean stones in these patients. In their study, 98 patients with urinary stone and BMI over 35 were studied. Results were evaluated according to the radiologic findings such as abdominal $\mathrm{x}$-ray, echography and CT scan. In 98 patients with an average BMI of $37.74 \mathrm{~kg} / \mathrm{m}^{2}, 133$ stones with an average diameter of $10.38 \mathrm{~mm}$ were found. Totally, $56.3 \%$ of patients were free from stone, $37.5 \%$ were suffering from remaining parts, and $6.2 \%$ were afflicted with treatment failure. Treatment efficacy was significantly related to patients' BMI which was similar to our study, however, regarding treatment complications our findings were not consistent with Olivi et al (12).

In the study by Yang et al, patients with solitary urinary stones, which was treated by ESWL were evaluated during these years. In 52 patients (25.6\%) ESWL was failed. Forty patients $(19.7 \%)$ needed re-treatment, while 12 patients were treated again with ESWL and 28 patients were treated by ureteroscopy. Patients with failed ESWL compared to patients who have been successful with ESWL had high weight, BMI and BC (buttock circumference). In univariate analysis, the size of stone and buttock circumference were determined as failure factors of EWSL. Similarly, BMI was identified as a factor with intermediate importance. Multivariate analysis showed that the size of stone is a clear factor in the failure of ESWL, while BC is an independent factor to defeat lithotripsy in middle and lower urinary stones. Likewise, BMI is an independent factor for upper urinary stones, which is consistent with our study (13).

In the study by Park et al, 573 patients with urinary stones between 5 and $20 \mathrm{~mm}$ were treated by ESWL (2006 to 2010). The successful group was defined as individuals who are free from stone in CT scan or radiography for six weeks after ESWL and unsuccessful group was determined as remaining particles of stone after six weeks of ESWL. The results of this study showed that the SSD influenced the results of ESWL (14). These findings are similar to our study too. In a retrospective study by Pareek et al on 1282 patients, ESWL was conducted on 83 patients (by electromagnetic lithotripsy). They found that SSD is an effective factor on efficacy of SWL. This finding is also similar to our study (11). Pareek et al also evaluated the effect of SSD on the obtained results of ESWL in lower pole kidney stones. In this study, 64 patients with lower pole kidney stones were evaluated (2000-2004). Stones diameter was between 0.5 to $1.5 \mathrm{~cm}$ and SSD was measured by CT scan. Radiological examinations of the kidneys, 
ureters and bladder within six weeks after lithotripsy divided patients into two groups of without and with stone. Of 64 patients, 30 patients were free of stones since 34 patients had a remained stone. Average SSD in stonesfree group was $8.12 \pm 1.74 \mathrm{~cm}$ while in group with stones it was $11.53 \pm 1.89 \mathrm{~cm}$. Juan et al showed the impact of SSD on the obtained results of ESWL while SSD more than 10 $\mathrm{cm}$ is likely led to treatment failure. Their results are also consistent with our finding (15).

In a study conducted by Jacobs et al, to assess the impact of SSD on the results of ESWL, 85 patients who were retrospectively treated by ESWL were assessed regarding their SSD. Stone-to-skin distance was measured using CT scan. Average SSD in patients without and with stones was not significant $(P=0.66$ and $P=0.94$ respectively). The study showed that SSD has no effect on the success rate of ESWL. This finding is in contrast to our study, which may be due to sample size (16).

\section{Conclusion}

In this study we concluded that BMI and SSD are factors affecting the treatment outcomes of ESWL. In low SSD, difference between the two groups was significant regarding treatment results. Additionally, we found BMI has no effect on complications of lithotripsy.

\section{Limitations of the study}

Our study was conducted on a limited proportion of patients. We suggest investigating calcium levels of urine in the future similar studies.

\section{Authors' contribution}

MS and FMAB conceived the study. MA performed the experiments. ZK drafted the final manuscript. All authors read, revised and approved the final manuscript.

\section{Conflicts of interest}

The authors declare no conflict of interest.

\section{Ethical considerations}

Ethical issues (including plagiarism, data fabrication, double publication) have been completely observed by the authors.

\section{Funding/Support}

Shahrekord University of Medical Sciences supported this research financially (Grant \# 2312, 2016).

\section{References}

1. Hwang I, Jung SI, Kim KH, Hwang EC, Yu HS, Kim SO,et. al. Factors influencing the failure of extracorporeal shock wave lithotripsy with Piezolith 3000 in the management of solitary ureteral stone. Urolithiasis. 2014; 42: 263-267. doi:

\subsection{7/s00240-014-0641-8}

2. Stamatelou KK, Francis ME, Jones CA, Nyberg LM, Curhan GC. Curhan Time trends in reported prevalence of kidney stones in the United States: 1976-1994. Kidney Int. 2003; 63:1817-23.

3. Scales CD Jr, Smith AC, Hanley JM, Saigal CS. Urologic Diseases in America Project. Prevalence of kidney stones in the United States. Eur Urol. 2012;62:160-5. doi: 10.1016/j. eururo.2012.03.052

4. Quan V, Kalin A. Sensitivity to meat protein intake and hyperoxaluria in idiopathic calcium stone formers. Kidney Int 2001;59:2273-81. doi: 10.1046/j.1523-1755.2001.00744.x

5. Nguyen QV, Kälin A, Drouve U, Casez JP, Jaeger P. Sensitivity to meat protein intake and hyperoxaluria in idiopathic calcium stone formers. Kidney Int. 2001;59:2273-81. doi: 10.1046/j.1523-1755.2001.00744.x

6. Healy KA, Ogank A. Nonsurgical management of urolithiasis: An overview of explusive therapy. J Enourol. 2005;19:759-67. doi: 10.1089/end.2005.19.759

7. Ajlouni K, Jaddou H, Batieha A. Obesity in Jordan. Int J Obes Relat Metab Disord. 1998;22:624-8.

8. Khader Y, Batieha A, Ajlouni H, El-Khateeb M, Ajlouni K. Obesity in Jordan: prevalence, associated factors, comorbidities, and change in prevalence over ten years. Metab Syndr Relat Disord 2008; 6:113-20. doi: 10.1089/ met.2007.0030

9. Sarica K. Obesity and stones. Curr Opin Urol. 2019; 29:2732. doi: 10.1097/MOU.000000000000055711.

10. Keshi X. Role of obesity on the effectiveness of the Extracorporeal Shock Wave Lithotripsy (ESWL) method. Eur Assoc Urol. 2018;17:e2577

11. Pareek G, Hedican SP, Lee FT. Nakada SY. Shock wave lithotripsy success determined by skin-to-stone distance on computed tomography. Urology. 2005;66:941. doi: 10.1016/j.urology.2005.05.011.

12. Olivi B, Vedrine N, Costilles T, Boiteux JP, Guy L. [Extra corporeal shock wave lithotripsy in patients with body mass index over $35 \mathrm{~kg} / \mathrm{m}^{2}$ ]. Prog Urol. 2011;21:254-9. doi: 10.1016/j.purol.2010.11.005

13. Yang TK, Yang HJ, Lee LM, Liao CH. Body mass index and buttock circumference are independent predictors of disintegration failure in extracorporeal shock wave lithotripsy for ureteral calculi. J Formos Med Assoc. 2013; 112:421-5.doi: 10.1016/j.jfma.2012.02.004

14. Park BH, Choi H, Kim JB, Chang YS. Analyzing the effect of distance from skin to stone by computed tomography scan on the extracorporeal shock wave lithotripsy stonefree rate of renal stones. Korean J Urol. 2012;53:40-3. doi: 10.4111/kju.2012.53.1.40.

15. Juan HC, Lin HY, Chou YH, Yang YH, Shih PM, Chuang $\mathrm{SM}$, et al. Abdominal fat distribution on computed tomography predicts ureteric calculus fragmentation by shock wave lithotripsy. Eur Radiol. 2012;22:1624-30. doi: 10.1007/s00330-012-2413-6.

16. Jacobs BL, SmaldoneMC, Smaldone AM, Ricchinuti DJ, Averch TD. Effect of skin-to stone distance on shockwave lithotripsy success. J Endourol. 2008; 22:1623-7. doi: 10.1089/end.2008.0169.

Copyright (c) 2019 The Author(s); Published by Nickan Research Institute. This is an open-access article distributed under the terms of the Creative Commons Attribution License (http://creativecommons.org/licenses/by/4.0), which permits unrestricted use, distribution, and reproduction in any medium, provided the original work is properly cited. 